\title{
BRE modulates granulosa cell death to affect ovarian follicle development and atresia in the mouse
}

\author{
Cheung Kwan Yeung ${ }^{1,5}$, Guang Wang ${ }^{1,2,5}$, Yao Yao ${ }^{3}$, Jianxin Liang ${ }^{1,2}$, Cheuk Yiu Tenny Chung ${ }^{3}$, Manli Chuai ${ }^{4}$, Kenneth Ka Ho Lee ${ }^{*, 3}$ and \\ Xuesong Yang ${ }^{*, 1}$
}

The BRE (brain and reproductive expression) gene, highly expressed in nervous and reproductive system organs, plays an important role in modulating DNA damage repair under stress response and pathological conditions. Folliculogenesis, a process that ovarian follicle develops into maturation, is closely associated with the interaction between somatic granulosa cell and oocyte. However, the regulatory role of BRE in follicular development remains undetermined. In this context, we found that BRE is normally expressed in the oocytes and granulosa cells from the primordial follicle stage. There was a reduction in follicles number of BRE mutant (BRE ${ }^{-l-}$ ) mice. It was attributed to increase the follicular atresia in ovaries, as a result of retarded follicular development. We established that cell proliferation was inhibited, while apoptosis was markedly increased in the granulosa cells in the absence of BRE. In addition, expressions of $\gamma-\mathrm{H} 2 \mathrm{AX}$ (marker for showing DNA double-strand breaks) and DNA damage-relevant genes are both upregulated in $\mathrm{BRE}^{-1-}$ mice. In sum, these results suggest that the absence of BRE, deficiency in DNA damage repair, causes increased apoptosis in granulosa cells, which in turn induces follicular atresia in $\mathrm{BRE}^{-1-}$ mice.

Cell Death and Disease (2017) 8, e2697; doi:10.1038/cddis.2017.91; published online 23 March 2017

BRE is expressed in a various tissues that include the adrenal glands, brain, heart, kidneys, testis and ovaries. ${ }^{1,2}$ The highest level of expression is in the nervous and reproductive systems, hence the gene was named $B R E$ (brain and reproductive expressed). BRE is now considered to be an adapter protein or a homeostatic protein, which plays a role in stress response and DNA damage repair by some yet unknown mechanisms. ${ }^{3}$ It has been reported that homeostasis is archived by modulating the action of hormones and cytokines in physiological and various pathological conditions (including inflammation, infection and cancers). ${ }^{4}$ In addition, BRE also acts as the TNFRSF1A modulator, as it can modulate TNF signaling by directly binding to TNFR-1. ${ }^{5}$ We have recently reported that BRE plays a vital role in controlling stem cell differentiation by maintaining stemness and also neurogenesis and somitogenesis during embryo gastrulation. ${ }^{6,7}$ However, little is known of the physiological and pathological function of BRE in the reproductive system, in which normally express high levels of BRE. We could cause the lack of obvious reproductive defects in BRE knockout mice for the delay of investigating BRE functions on reproductive biology. Apparently, more elaborative studies on reproductive system are indispensable to elucidate whether or not BRE gene have functions in reproductive activities. Hence, we generated BRE mutant mice and carefully examined the development of ovarian follicles in these mice to elucidate how the absence of BRE affects crucial events during folliculogenesis.
Ova are the female reproductive cells that reside and develop within the ovaries, a pair of ductless female reproductive glands. The ovarian follicle, as the functional unit of the ovary, is morphologically composed of an oocyte surrounded by granulosa and theca cells. These cells protect and support the development of the oocytes. Given the appropriate hormonal environment, primordial follicles are induced to develop through the primary, secondary and mature follicular stages. However, most of follicles normally degenerate to be atretic follicles, which could occur in every stages of follicular development. ${ }^{8}$ At birth, the ovary contains approximately one million hibernating primordial follicles and some of them become activated to undergo folliculogenesis during puberty. The various developmental stages that the activated primordial follicles pass through during folliculogenesis are also shared by many animals.

Ovarian follicle development is precisely regulated by a sequence of autocrine and paracrine factors. In addition, with input from endocrine hormones that includes pituitary and ovarian hormones. It is especially the balance of these hormones that determines whether a developing follicle becomes maturated or undergoes atresia. ${ }^{9-11}$ Among these hormones, follicle-stimulating hormone (FSH) is the most important, playing a role in the survival of early antral-staged follicles and the growth, activation and differentiation of prenatal follicles. $^{12,13}$

\footnotetext{
${ }^{1}$ Division of Histology and Embryology, Key Laboratory for Regenerative Medicine of the Ministry of Education, Medical College, Jinan University, Guangzhou 510632, China; ${ }^{2}$ Chinese Medicine College, Jinan University, Guangzhou 510632, China; ${ }^{3}$ Key Laboratory for Regenerative Medicine of the Ministry of Education, School of Biomedical Sciences, Chinese University of Hong Kong, Shatin, Hong Kong and ${ }^{4}$ Division of Cell and Developmental Biology, University of Dundee, Dundee DD1 5EH, UK ${ }^{*}$ Corresponding author: X Yang, Division of Histology and Embryology, Key Laboratory for Regenerative Medicine of the Ministry of Education, Medical College, Jinan University, Guangzhou 510632, China. Tel: +86 0208522 8316; Fax: +86 0208522 1343; E-mail: yang_xuesong@ 126.com

or KKH Lee, Key Laboratory for Regenerative Medicine of the Ministry of Education, School of Biomedical Sciences, Chinese University of Hong Kong, Shatin, Hong Kong. Tel: (852) 3943 6785; Fax: (852) 2603 7902; E-mail: kaholee@cuhk.edu.hk

${ }^{5}$ These authors contributed equally to this work.

Received 05.10.16; revised 09.1.17; accepted 09.2.17; Edited by M Agostini
} 
The cellular and molecular mechanisms that determine the developmental fate of ovarian follicles is still poorly understood. ${ }^{14}$ There is now accumulating evidences that indicate the death of follicular granulosa cells is partly responsible for causing follicular atresia. ${ }^{15,16}$ Granulosa cells could become apoptotic by interfering with steroidogenesis and the addition of dexamethasone, which in turn trigger follicular atresia. In contrast, insulin-like growth factor (IGF) could protect the granulosa cells from apoptosis, induced by dexamethasone, which in turn represses follicular atresia. ${ }^{17}$ In this context, we have investigated whether BRE is involved in regulating follicular development and atresia-through its effect on granulosa cell survival. We systematically examined the development of the ovarian follicles in BRE mutant mice and specially focused on the correlation between follicular atresia and granulosa cell growth and death.

\section{Results}

BRE mutation reduces ovarian size and weight. To investigate the role of BRE in ovarian development, we first measured the weights of freshly collected $\mathrm{BRE}^{+/+}, \mathrm{BRE}^{+/-}$and
$\mathrm{BRE}^{-/-}$ovaries. Six ovaries from each group were measured and weighed (Figure 1). We determined that the average size and weight of $\mathrm{BRE}^{-1-}$ ovaries were both markedly reduced compared with $\mathrm{BRE}^{+/-}$and $\mathrm{BRE}^{+/+}$ovaries. There was no significant difference between $\mathrm{BRE}^{+/-}$and $\mathrm{BRE}^{+/+}$ovaries. The average volume of $\mathrm{BRE}^{+/+}, \mathrm{BRE}^{+/-}$and $\mathrm{BRE}^{-/-}$ovaries were $3.19 \pm 0.26,2.91 \pm 0.27$ and $1.48 \pm 0.25 \mathrm{~mm}^{3}$, respectively (Figure 1b). The average weight of $\mathrm{BRE}^{+/+}, \mathrm{BRE}^{+/-}$and $\mathrm{BRE}^{-/-}$ovaries was $2.63 \pm 0.19,2.7 \pm 0.22$ and $1.4 \pm 0.21 \mathrm{mg}$, respectively (Figure $1 \mathrm{c}$ ).

We next examined the BRE express pattern in the ovaries using immunofluorescent staining. The result revealed that BRE was expressed in the oocytes of primordial and primary $\mathrm{BRE}^{+/+}$ follicles (Figures 1d and d1), and the granulosa cells of secondary and antral follicles (Figures $1 \mathrm{~d} 2$ and $\mathrm{d} 3$ ). The expression pattern in $\mathrm{BRE}^{+/-}$follicles was similar to $\mathrm{BRE}^{+/+}$ follicles (Figures 1e and e1). Not unexpectedly, BRE was not expressed in $\mathrm{BRE}^{-/}$ovaries, apart from autofluorescence from red blood cells (Figure 1f). The BRE expression pattern suggests that the gene might play a role in ovarian follicle development.

\section{BRE mutation reduces number of follicles in the ovaries.} The numbers and types of growing follicles were estimated

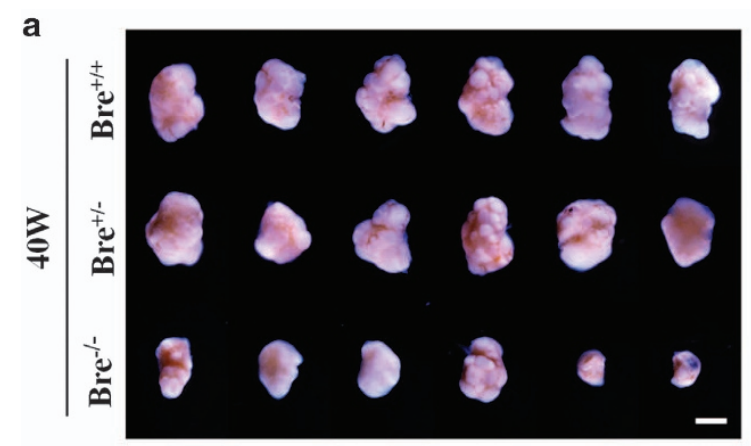

b

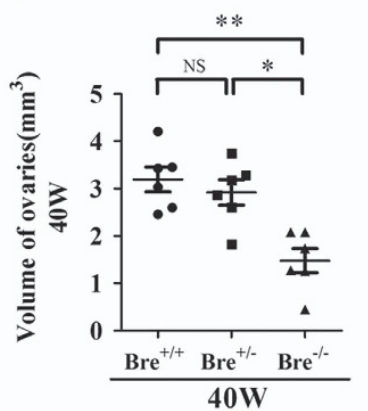

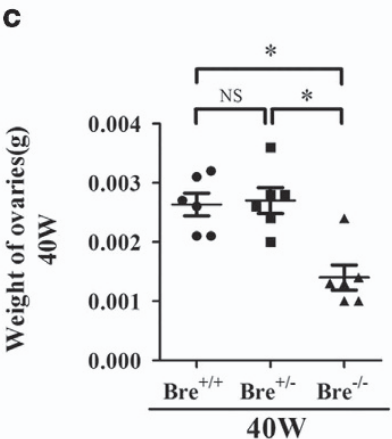

$\mathrm{BRE}^{-/-}$
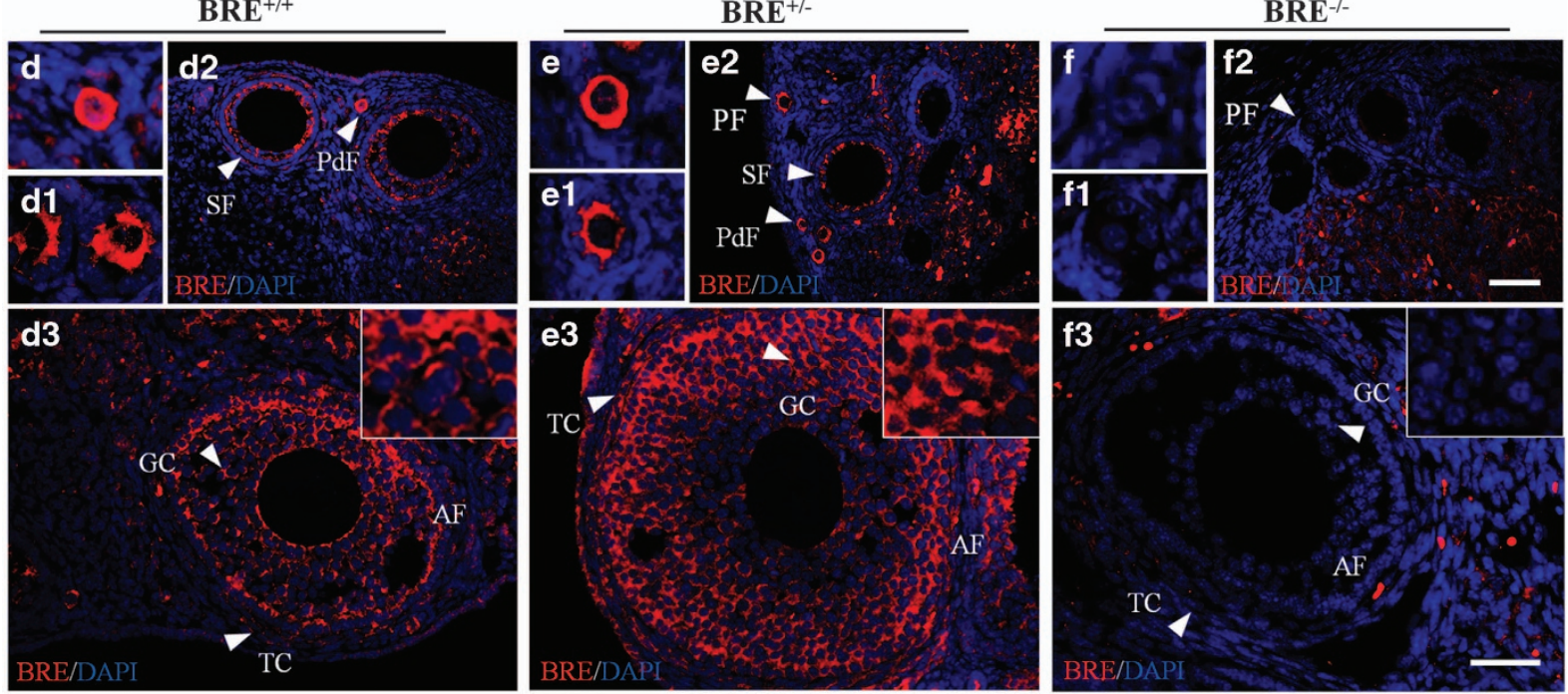

Figure 1 BRE knockout mice produce smaller ovaries. (a) Representative appearance of 40-week-old $\mathrm{BRE}^{+/+}$, $\mathrm{BRE}^{+/-}$and $\mathrm{BRE}^{-/-}$ovaries. (b and c) Plot charts comparing the ovarian volumes (b) and weights amongst the three groups of ovaries. (d-f) Representative immunofluorescent micrographs of $\mathrm{BRE}^{+/+}(\mathbf{d})$, BRE ${ }^{+/-}(\mathbf{e})$ and $\mathrm{BRE}^{-1-}$ (f) ovarian sections stained with BRE antibodies. The staining confirms that BRE ${ }^{-}$- mutant primordial (f), primary (f1), secondary (f2) and antral (f3) follicles do not express $\mathrm{BRE}$. Furthermore, in $\mathrm{BRE}^{+/+}$and $\mathrm{BRE}^{+/-}$follicles, $\mathrm{BRE}$ is manly expressed in the granulosa cells (d and e). PdF, primordial follicle; PF, primary follicle; SF, secondary follicle; TC, theca cells; GC, granulosa cells. Scale bars $=1000 \mu \mathrm{m}$ in a; $50 \mu \mathrm{m}$ in d2, e2 and f2; $50 \mu \mathrm{m}$ in d3, e3, f3 

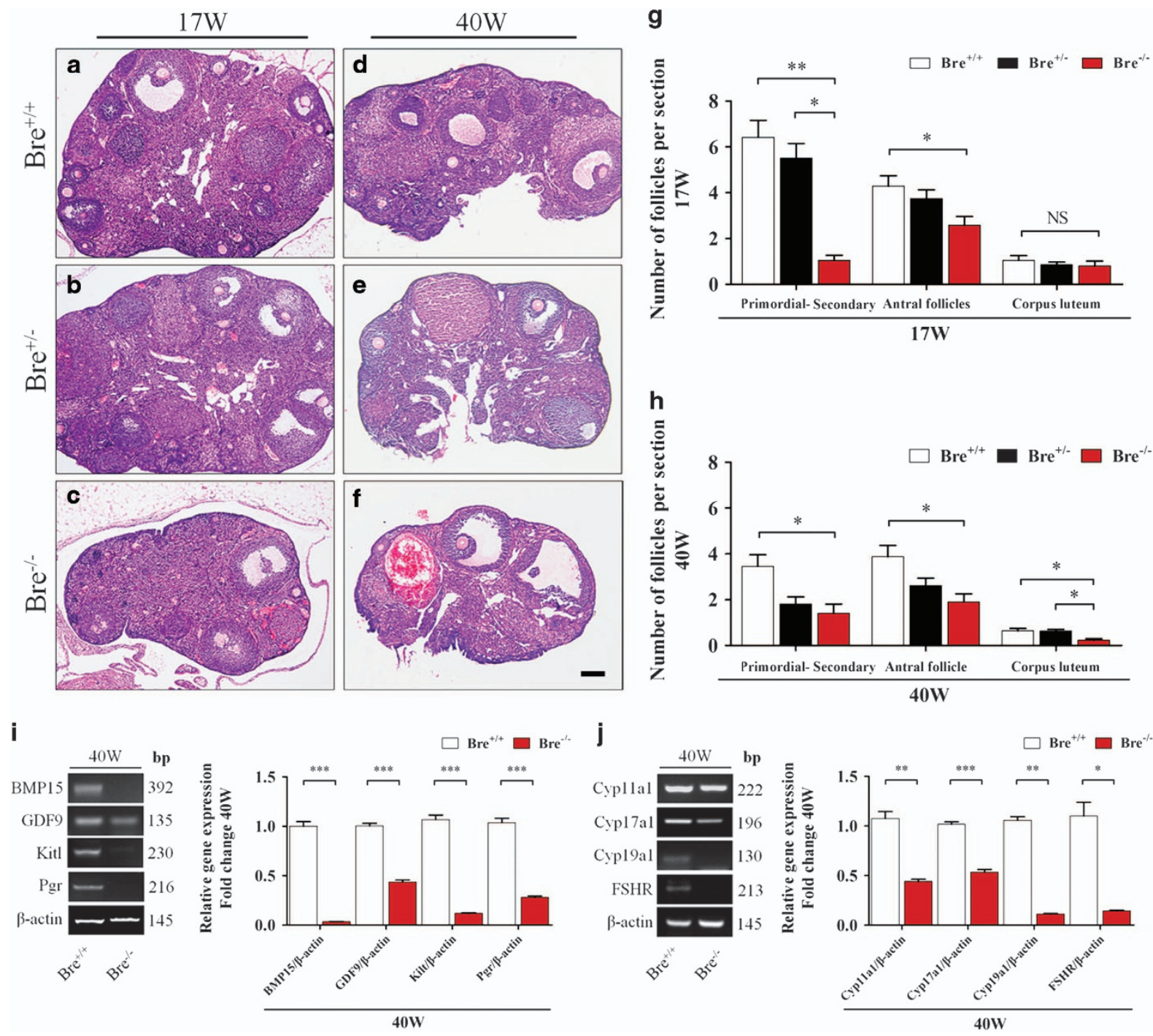

Figure 2 Follicle development in BRE-wild-type and -knockout ovaries. (a-f) Representative histological appearance of 17- and 40-week-old BRE ${ }^{+/+}$(a and d), BRE ${ }^{+-}$ ( $\mathbf{b}$ and $\mathbf{e}$ ) and BRE ${ }^{-1-}$ (c and f) ovaries stained with hematoxylin and eosin. ( $\mathbf{g}$ and $\mathbf{h}$ ) Bar charts comparing the number of follicles at different stages of development in 17- (g) and 40- (h) week-old $\mathrm{BRE}^{+/+}, \mathrm{BRE}^{+/-}$and BRE ${ }^{-/-}$ovaries. (i) Semiquantitative RT-PCR analysis revealed that BMP15, GDP9, Kit1 and Pgr expression was significantly reduced in 40-week $\mathrm{BRE}^{-1-}$ mouse ovaries. (j) Semiquantitative RT-PCR analysis also showed that Cyp11a1, Cyp17a1, Cyp19a1 and FSHR expression significantly decreased. Scale bar $=200 \mu \mathrm{m}$ in a-f

from serial stained sections of 17- and 40-week-old $\mathrm{BRE}^{+/+}$, $\mathrm{BRE}^{+/-}$and $\mathrm{BRE}^{-/-}$ovaries (Figures 2a-f). The results revealed that the numbers of primordial, primary, secondary and antral follicles were significantly decreased in 17-week $\mathrm{BRE}^{+/-}$and $\mathrm{BRE}^{-1-}$ ovaries as compared with $\mathrm{BRE}^{++}$ ovaries. However, there was no significant difference in the number of corpus luteum found between the three groups. It was estimated that in 17-week-old ovaries, the average number of follicles were significantly reduced in $\mathrm{BRE}^{-/-}$mice compared with $\mathrm{BRE}^{+/+}$mice $(P<0.05$; for primordial-secondary follicles: in $\mathrm{BRE}^{+/+}=6.4 \pm 0.7, \mathrm{BRE}^{+/-}=5.5 \pm 0.6$ and $\mathrm{BRE}^{-/-}=1.0 \pm 0.2$; for antral follicles: $\mathrm{BRE}^{+/+}=4.3 \pm 0.4$, $\mathrm{BRE}^{+/-}=3.7 \pm 0.4$ and $\mathrm{BRE}^{-/-}=2.6 \pm 0.4$; for corpus luteum: $\mathrm{BRE}^{+/+}=1.0 \pm 0.2, \quad \mathrm{BRE}^{+/-}=0.9 \pm 0.1 \quad$ and $\mathrm{BRE}^{-/-}$ $=0.8 \pm 0.2, n=6$ in each group, Figure $2 \mathrm{~g}$ ). The types of follicles found in 40-week-old ovaries were also counted. It was determined that the numbers of follicles and corpus luteum were significantly reduced in $\mathrm{BRE}^{-/-}$ovaries as compared with $\mathrm{BRE}^{+/+}$(for primordial-secondary follicles: $\mathrm{BRE}^{+/+}$ $=3.5 \pm 0.5, \mathrm{BRE}^{+/-}=1.8 \pm 0.3$ and $\mathrm{BRE}^{-1-}=1.4 \pm 0.4$. For antral follicles: $\mathrm{BRE}^{+/+}=3.9 \pm 0.5, \mathrm{BRE}^{+/-}=2.6 \pm 0.3$ and $\mathrm{BRE}^{-/-}=1.9 \pm 0.3$. For corpus luteum: $\mathrm{BRE}^{+/+}=0.6 \pm 0.1$, $\mathrm{BRE}^{+/-}=0.6 \pm 0.1$ and $\mathrm{BRE}^{-1-}=0.2 \pm 0.1, n=6, P<0.05$, Figure 2h).

Using RT-PCR approach, we examined the expressions of genes known to be associated with follicular development, in 40-week-old $\mathrm{BRE}^{+/+}$and $\mathrm{BRE}^{-/-}$ovaries. The results demonstrated that bone morphogenetic protein 15 (BMP15), growth differentiation factor 9 (GDF9), Kit1, Pgr, Cyp11a1, Cyp17a1, Cyp19a1 and FSHR expressions were significantly 


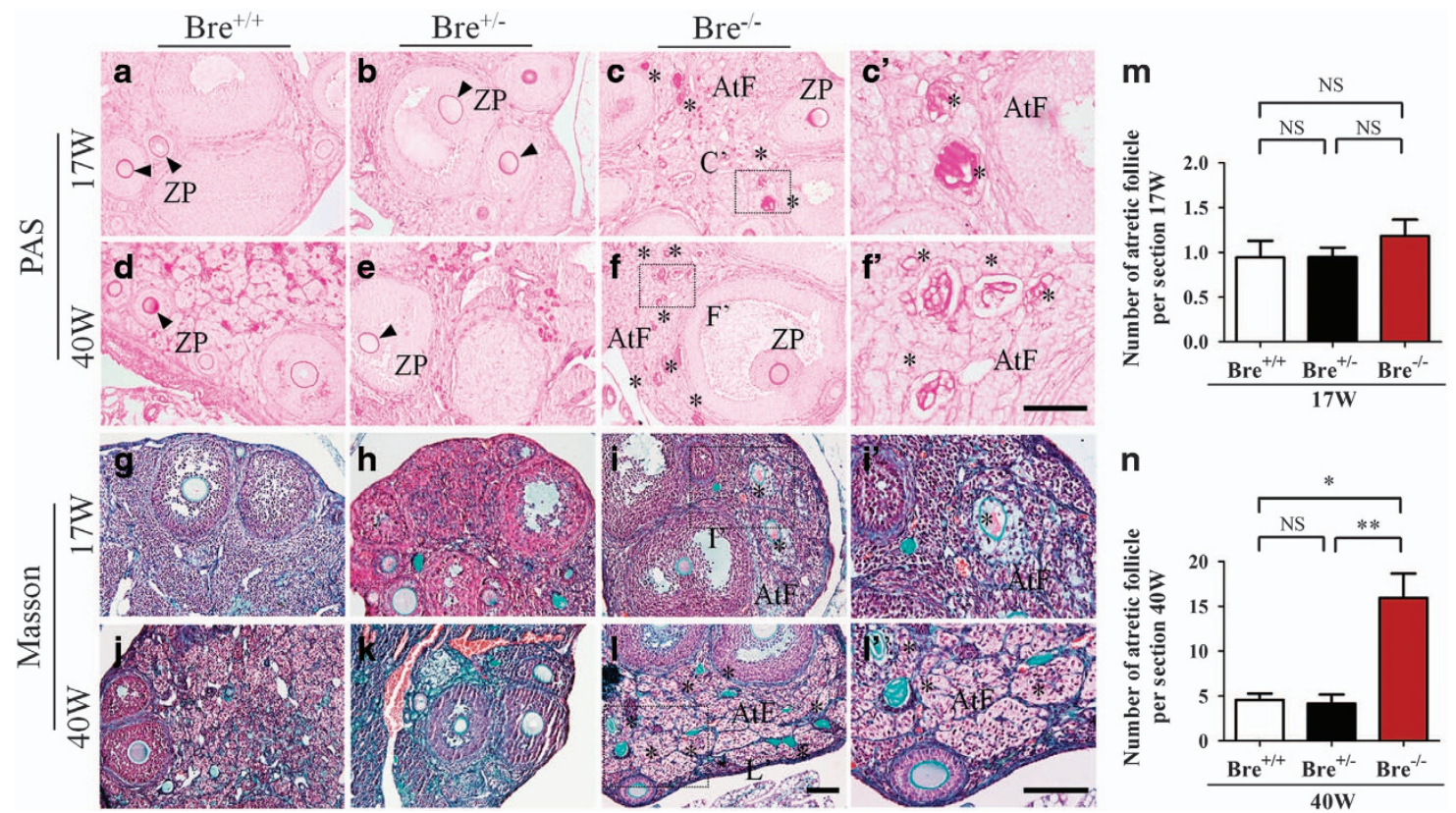

Figure 3 Ovarian sections stained with specialized dyes. Representative micrographs of 17- and 40-week-old ovarian sections stained with PAS (a-f') and Masson's trichrome stain $\left(\mathbf{g}-\mathbf{I}^{\prime}\right)$. (i' and $\left.\mathbf{I}^{\prime}\right)$ Higher-magnification images of the regions highlighted by the dotted squares in $\mathbf{i}$ and $\mathbf{I}$, respectively. ( $\mathbf{m}$ and $\mathbf{n}$ ) Bar charts comparing the number of atretic follicles in 17- (m) and 40- (n) week-old BRE ${ }^{+/+}, \mathrm{BRE}^{+/-}$and BRE ${ }^{-l-}$ ovaries. AtF, atretic follicle; ZP, zona pellucida. Scale bar $=100 \mu \mathrm{m}$ in a-l; $50 \mu \mathrm{m}$ in $\mathbf{c}^{\prime}$ and $\mathbf{f}^{\prime}$; $100 \mu \mathrm{m}$ in $\mathrm{i}^{\prime}$ and $\mathrm{I}^{\prime}$

repressed in $\mathrm{BRE}^{-/-}$ovaries compared to their wild-type counterpart (BMP15, ${ }^{* \star *} P<0.001$; GDF9, ${ }^{\star * \star} P<0.001$; Kit1, ${ }^{* * *} P<0.001 ; \quad$ Pgr, $\quad{ }^{* * *} P<0.001 ;$ Cyp11a1, $\quad{ }^{* *} P<0.01$; Cyp17a1, ${ }^{* * *} P<0.001 ; \quad$ Cyp19a1, ${ }^{* *} P<0.01 ; \quad$ FSHR, ${ }^{*} P<0.05 ; n=3$ for each group, Figures $2 \mathrm{i}$ and $\left.\mathrm{j}\right)$. The results suggest that BRE is required for follicle development and maturation, and the blocking of these processes would lead to follicle atresia.

BRE mutation enhances follicular atresia. Histological sections of 17 (young)- and 40 (old)-week-old $\mathrm{BRE}^{+/+}$, $\mathrm{BRE}^{+/-}$and $\mathrm{BRE}^{-/-}$ovaries were stained with Masson and periodic acid Schiff (PAS) staining to reveal the extent of atresia in these ovaries (Figure 3). The high magnification of the zona pellucida shows its distinct contraction in the atretic follicles, as demonstrated in Figures $3 \mathrm{c}^{\prime}$. Using these as markers, we methodically counted the numbers of atretic follicles present in the three groups of ovaries. The results showed that the number of atretic follicles increased in young $\mathrm{BRE}^{-/-}$ovaries (17 weeks old: $\mathrm{BRE}^{+/+}=0.9 \pm 0.2, \mathrm{BRE}^{+/-}$ $=0.9 \pm 0.1$ and $\mathrm{BRE}^{-1-}=1.2 \pm 0.2 \quad n=6, \quad P>0.05$, Figure $3 \mathrm{~m})$. The number of atretic follicles were significantly increased in old $\mathrm{BRE}^{-/-}$ovaries (40 weeks old: $\mathrm{BRE}^{+/+}$ $=4.6 \pm 0.7, \mathrm{BRE}^{+/-}=4.2 \pm 1.0$ and $\mathrm{BRE}^{-/-}=15.9 \pm 2.7$, $n=6,{ }^{* *} P<0.01,{ }^{*} P<0.05$; Figure $3 n$ ).

BRE mutation represses granulosa cell proliferation. The relationship between BRE and granulosa cell proliferation was investigated. Longitudinal sections of 17- and 40-week-old $\mathrm{BRE}^{+/+}, \mathrm{BRE}^{+/-}$and $\mathrm{BRE}^{-/-}$ovaries were immunofluorescently stained with proliferating cell nuclear antigen (PCNA) antibody (Figures 4a-f). Examination revealed that the number of $\mathrm{PCNA}^{+}$granulosa cells (arrows) in both 17- and 40-week $\mathrm{BRE}^{-/-}$ovaries were significantly reduced compared with $\mathrm{BRE}^{+/+}$ovaries (PCNA, 17 weeks: $\mathrm{BRE}^{+/+}=80.75 \pm 2.16, \mathrm{BRE}^{+/-}=62.13 \pm 4.07$ and $\mathrm{BRE}^{-/-}$ $=36.44 \pm 4.95, n=6,{ }^{* * *} P<0.001$, Figure $4 \mathrm{~g} ; 40$ weeks: $\mathrm{BRE}^{+/+}=64.53 \pm 11.18, \mathrm{BRE}^{+/-}=51.94 \pm 7.26$ and $\mathrm{BRE}^{-/-}$ $=12.77 \pm 4.49, n=6,{ }^{\star \star} P<0.01,{ }^{\star} P<0.05$, Figure $\left.4 \mathrm{~h}\right)$. In addition, the number of $\mathrm{BrdU}^{+}$granulosa cells were significantly decreased compared with 17-week-old $\mathrm{BRE}^{+/+}$ ovaries (BrdU, $\mathrm{BRE}^{++}=52.26 \pm 2.16, \quad \mathrm{BRE}^{-/-}=16.46 \pm$ $1.90, n=6,{ }^{* * *} P<0.001$, Supplementary Figures S3A-D). The results indicated that the number of replicating granulosa cells was significantly reduced in the absence of BRE (Figure 4q). Using the same strategy, we also immunohistochemical stained the sections using pHIS3 antibody (Figures 4i-n). Interestingly, we did not find that any significant difference between the number of $\mathrm{pHIS3}^{+}$granulosa cells (arrows) in both 17- and 40-week-old $\mathrm{BRE}^{-1-}$ and $\mathrm{BRE}^{+/+}$mouse ovaries (pHIS3, 17 weeks: $\mathrm{BRE}^{+/+}=3.84$ $\pm 0.84, \mathrm{BRE}^{+/-}=3.02 \pm 0.54$ and $\mathrm{BRE}^{-/-}=4.04 \pm 1.06$, $n=6$, Figure 40; 40 weeks: $\mathrm{BRE}^{+/+}=1.92 \pm 0.19, \mathrm{BRE}^{+/-}$ $=1.31 \pm 0.37$ and $\mathrm{BRE}^{-1-}=1.66 \pm 0.28, \quad P>0.05$, Figure $4 p$ ). This might imply that BRE may mainly exerting its effect at the G1-S phase of the cell cycle (Figure 4q).

In order to determine how BRE targets the cell cycle during granulosa cell proliferation, we silenced the BRE expression levels through transfection with Control-siRNA or BRE-siRNA in COV434 cells. We can found more necrotic cells in the BRE-siRNA compared with the Control-siRNA group (black arrows, Supplementary Figures S3E and F). Quantitative PCR (qPCR) analysis was also performed to confirm that the expression level of BRE was downregulated after BRE-siRNA 

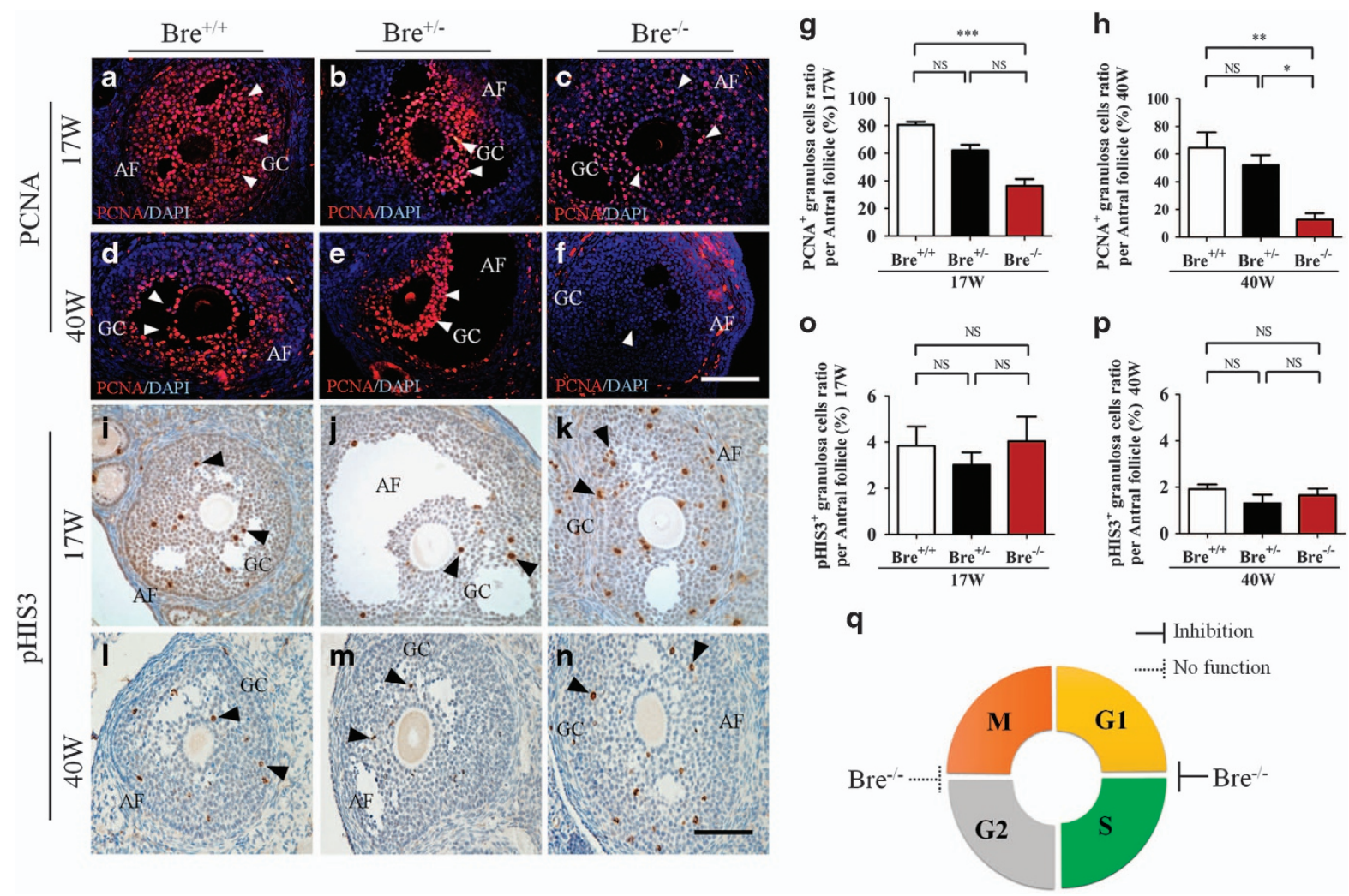

Figure 4 Ovarian sections immunofluorescently stained for PCNA and pHIS3. Representative micrographs of developing follicles stained for PCNA (a-f) and pHIS3 (i-n) to demonstrate the extent of granulosa cell proliferation in the follicles. ( $g$ and $\mathbf{h}$ ) Bar charts comparing the average number of PCNA ${ }^{+}$granulosa cells in antral follicles of $17-(\mathbf{g})$ and 40- (h) week-old BRE ${ }^{+/}, \mathrm{BRE}^{+/}$and BRE ${ }^{-/}$ovaries. (o and $\mathbf{p}$ ) Bar charts comparing the average number of pHIS3 ${ }^{+}$granulosa cells in antral follicles. (q) Pie chart predicting where BRE targets the cell cycle during granulosa cell proliferation (as predicted from the BRE ${ }^{-1}$ - results). AF, antral follicle; GC, granulosa cells. Scale bar $=100 \mu \mathrm{m}$ in a-n

transfection $48 \mathrm{~h}$ (Supplementary Figure S3G). To test whether the cell cycle progression pattern accounts for the marked differences after BRE-siRNA trasfection, we analyzed cell cycle patterns by propidium iodide $(\mathrm{PI})$ staining. After BRE-siRNA transfection $48 \mathrm{~h}$, we found COV434 cells showed a unique cell cycle pattern with a high percentage of G1 cells (Control-siRNA $=58.73 \pm 0.89, \quad$ BRE-siRNA $=72.50 \pm 4.12$, $n=3,{ }^{*} P<0.05$, Supplementary Figure $\mathrm{S} 3 \mathrm{H}$ ) and low percentage of G2/M cells (Control-siRNA $=8.72 \pm 1.64$, BREsiRNA $=0.49 \pm 0.49, \quad n=3, \quad{ }^{* *} P<0.01, \quad$ Supplementary Figure $\mathrm{S} 3 \mathrm{H}$ ). After BRE-siRNA transfection $72 \mathrm{~h}$, we found COV434 cells showed a unique cell cycle pattern with a high percentage of $\mathrm{G} 1$ cells (Control-siRNA $=59.37 \pm 0.23$, BREsiRNA $=64.03 \pm 0.67, \quad n=3, \quad{ }^{* *} P<0.01, \quad$ Supplementary Figure S3I), low percentage of $S$ cells (Control-siRNA $=37.93$ $\pm 0.95, \quad$ BRE-siRNA $=24.57 \pm 0.77, \quad n=3, \quad{ }^{* * *} P<0.001$, Supplementary Figure S3I) and high percentage of $\mathrm{G} 2 / \mathrm{M}$ cells (Control-siRNA $=2.67 \pm 0.80, \quad B R E-s i R N A=11.40 \pm$ 1.42, $n=3,{ }^{* *} P<0.01$, Supplementary Figure S3I). We also detected the expression levels of cell cycle-related genes using qPCR. The results showed that downregulating RBE with BRE-siRNA transfection significantly changed the expression levels of CyclinA, CyclinB, CyclinD1 and p53 compared with the Control-siRNA group. However, the CyclinE1 was significantly downregulated by BRE-siRNA transfection (CyclinA, $P>0.05$; CyclinB, $P>0.05$; CyclinD1,
$P>0.05 ;$ CyclinE1, ${ }^{*} P<0.05 ; \quad n=9$ for each group, Supplementary Figure S3J). Although upregulating genes included p21 and p27 (p21, ${ }^{* \star *} P<0.001 ; \mathrm{p} 27,{ }^{*} P<0.05 ; n=9$ for each group, Supplementary Figure S3J), indicating that the change in the cell cycle-related gene expression might partially be responsible for the phenotype induced by silencing BRE.

BRE mutation enhances granulosa cell death. We investigated whether BRE was involved in regulating apoptosis in the follicular granulosa cells. This was archived by immunofluorescently staining sections, prepared from 17- and 40-week-old $\left(\mathrm{BRE}^{+/+}, \mathrm{BRE}^{+/-}\right.$and $\mathrm{BRE}^{-1-}$ ) ovaries, with cleaved Caspase-3 (C-Caspase3) antibodies (Figures 5a-f). The result showed that the number of $\mathrm{C}$-Caspase $3^{+}$ granulosa cells (indicated by arrows) were significantly increased compared with 40-week-old $\mathrm{BRE}^{+/+}$ovaries (C-Caspase3 17 weeks: $\mathrm{BRE}^{+/+}=4.73 \pm 1.35, \mathrm{BRE}^{+/-}$ $=5.78 \pm 1.10$ and $\mathrm{BRE}^{-1-}=6.25 \pm 1.48, n=6$, Figure $5 \mathrm{~g}$; 40 weeks: $\mathrm{BRE}^{+/+}=1.93 \pm 1.23, \mathrm{BRE}^{+/-}=6.72 \pm 2.50$ and $\mathrm{BRE}^{-l-}=13.04 \pm 1.23, n=6,{ }^{\star \star} P<0.01$, Figure $5 \mathrm{~h}$ ). The results indicate that there were significantly more apoptotic granulosa cells in the BRE mutants in 40 weeks.

Seventeen- and forty-week-old ovarian sections produced from $\mathrm{BRE}^{+/+}, \mathrm{BRE}^{+/-}$and $\mathrm{BRE}^{-/-}$mice were also immunofluorescently stained for FasL (Figures 6a-f) and Fas 


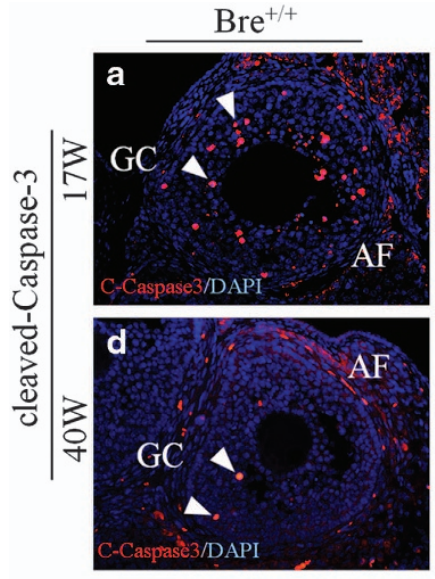

g

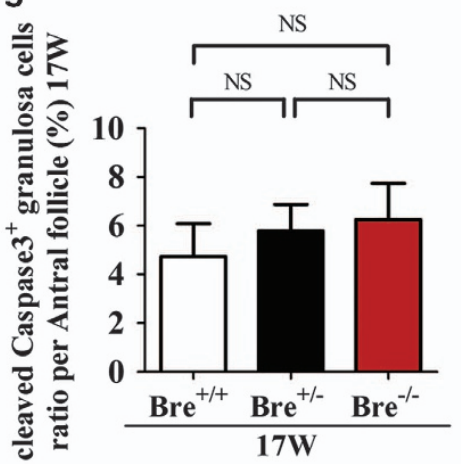

$\mathrm{Bre}^{+/-}$
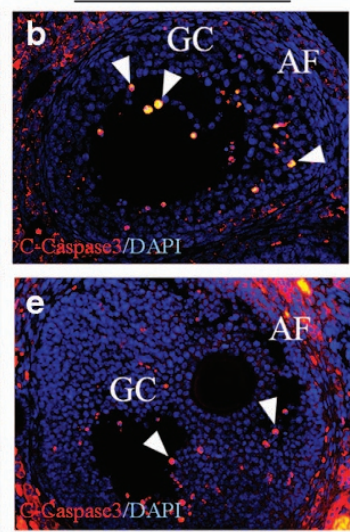

h

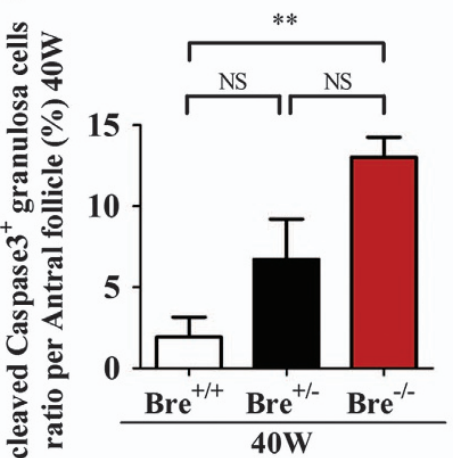

Figure 5 Ovarian sections stained for cleaved-Capase-3. (a-f) Representative micrographs of antral follicles immunofluorescently stained for c-Capase3 in 17- (a-c) and $40-(\mathbf{d}-\mathbf{f})$ week-old $\mathrm{BRE}^{+/+}, \mathrm{BRE}^{+/-}$and BRE ${ }^{-1-}$ ovaries. ( $\mathbf{g}$ and $\mathbf{~}$ ) Bar charts showing the average number of c-Capase $3^{+}$granulosa numbers in antral follicles from 17- (g) and 40 - (h) week-old $\mathrm{BRE}^{+/+}, \mathrm{BRE}^{+/-}$and $\mathrm{BRE}^{-/-}$ovaries. AF, antral follicle; GC, granulosa cells. Scale bar $=100 \mu \mathrm{m}$ in a-f

(Figures 6i-n). These two proteins play important roles in regulating apoptosis. The stained sections were analyzed to determine the ratio of $\mathrm{FasL}^{+}$and $\mathrm{Fas}^{+}$area (arrows) over the total area of granulosa cells. Statistical analysis revealed that the ratios for both $\mathrm{FasL}^{+}$and $\mathrm{Fas}^{+}$were significantly increased in comparison with $\mathrm{BRE}^{+/+}$mice $\left(\mathrm{FasL}^{+} 17\right.$ weeks: $\mathrm{BRE}^{+/+}$ $=0.60 \pm 0.16, \quad \mathrm{BRE}^{+/-}=0.10 \pm 0.03$ and $\mathrm{BRE}^{-/-}=7.34$ $\pm 2.26, n=6,{ }^{* * *} P<0.001$, Figure $6 \mathrm{~g} ; \mathrm{FasL}^{+} 40$ weeks: $\mathrm{BRE}^{+/+}=0.48 \pm 0.16, \mathrm{BRE}^{+/-}=0.41 \pm 0.30$ and $\mathrm{BRE}^{-/-}$ $=7.34 \pm 2.26, n=6,{ }^{*} P<0.05$, Figure $6 \mathrm{~h}$; $\mathrm{Fas}^{+} 17$ weeks: $\mathrm{BRE}^{+/+}=1.79 \pm 0.31, \quad \mathrm{BRE}^{+/-}=2.59 \pm 0.27$ and $\mathrm{BRE}^{-/-}$ $=5.55 \pm 1.06, n=6,{ }^{\star \star} P<0.01$, Figure 60 ; $\mathrm{Fas}^{+} 40$ weeks: $\mathrm{BRE}^{+/+}=0.86 \pm 0.27, \mathrm{BRE}^{+/-}=1.36 \pm 0.33$ and $\mathrm{BRE}^{-/-}$ $=8.94 \pm 2.44, n=6,{ }^{\star \star} P<0.01,{ }^{\star} P<0.05$, Figure $\left.6 p\right)$. The results suggest that the Fas/FasL signaling pathway is involved in the regulation of cell apoptosis modulated by BRE.

BRE mutation increases DNA damage susceptibility in granulosa cells. Seventeen- and forty-week-old $\mathrm{BRE}^{+/+}$, $\mathrm{BRE}^{+/-}$and $\mathrm{BRE}^{-/-}$ovaries were immunohistochemically stained using $\gamma-\mathrm{H} 2 \mathrm{AX}$ to establish whether BRE was involved in DNA damage repair (Figures $7 a-f)$. The results clearly demonstrated that the number of $\gamma-\mathrm{H}_{2} \mathrm{AX}^{+}$granulosa cells (indicated by arrows) in both 17- and 40-week-old $\mathrm{BRE}^{-1-}$ ovaries was significantly increased in comparison with control $\mathrm{BRE}^{+/+}$ovaries $\left(\gamma-\mathrm{H} 2 \mathrm{AX} 17\right.$ weeks $\mathrm{BRE}^{+/+}=0.45 \pm 0.08$,
$\mathrm{BRE}^{+/-}=1.28 \pm 0.19$ and $\mathrm{BRE}^{-/-}=5.40 \pm 0.97, \quad n=6$, ${ }^{\star *} P<0.01$, Figure 7g; 40 weeks: $\mathrm{BRE}^{+/+}=0.69 \pm 0.24$, $\mathrm{BRE}^{+/-}=0.81 \pm 0.45$ and $\mathrm{BRE}^{-/-}=5.10 \pm 1.07, n=6$, ${ }^{* *} P<0.05$, Figure $7 \mathrm{~h}$ ). Expression of genes associated with DNA damage repair (ATM, PUMA, Fas and p53) was also examined by semiquantitative RT-PCR. The results showed that PUMA and Fas expression markedly increased in the absence of BRE, whereas there was no significant change in ATM and p53 expression (ATM, $P>0.05$; PUMA, ${ }^{\star \star} P<0.01$; Fas, ${ }^{\star \star} P<0.01 ;$ p53, $P>0.05 ; n=3$ for each group, Figure 7i). These findings suggest that, in the absence of $\mathrm{BRE}$, there was significantly more DNA damage in the granulosa cells.

\section{Discussion}

In this study, we first examined and compared the morphology of wide-type and BRE knockout ovaries-as BRE is highly expressed in the reproductive system. We determined that the average weight and size of the BRE mutant ovaries were significantly smaller than wild-type ovaries-even though there was no difference between the overall weights of these mice. This suggests that BRE might play a specific role in ovarian follicle development. BRE immunofluorescent staining revealed that $\mathrm{BRE}$ was strongly expressed in the oocyte at primordial follicle stage and then it was reverted to the 

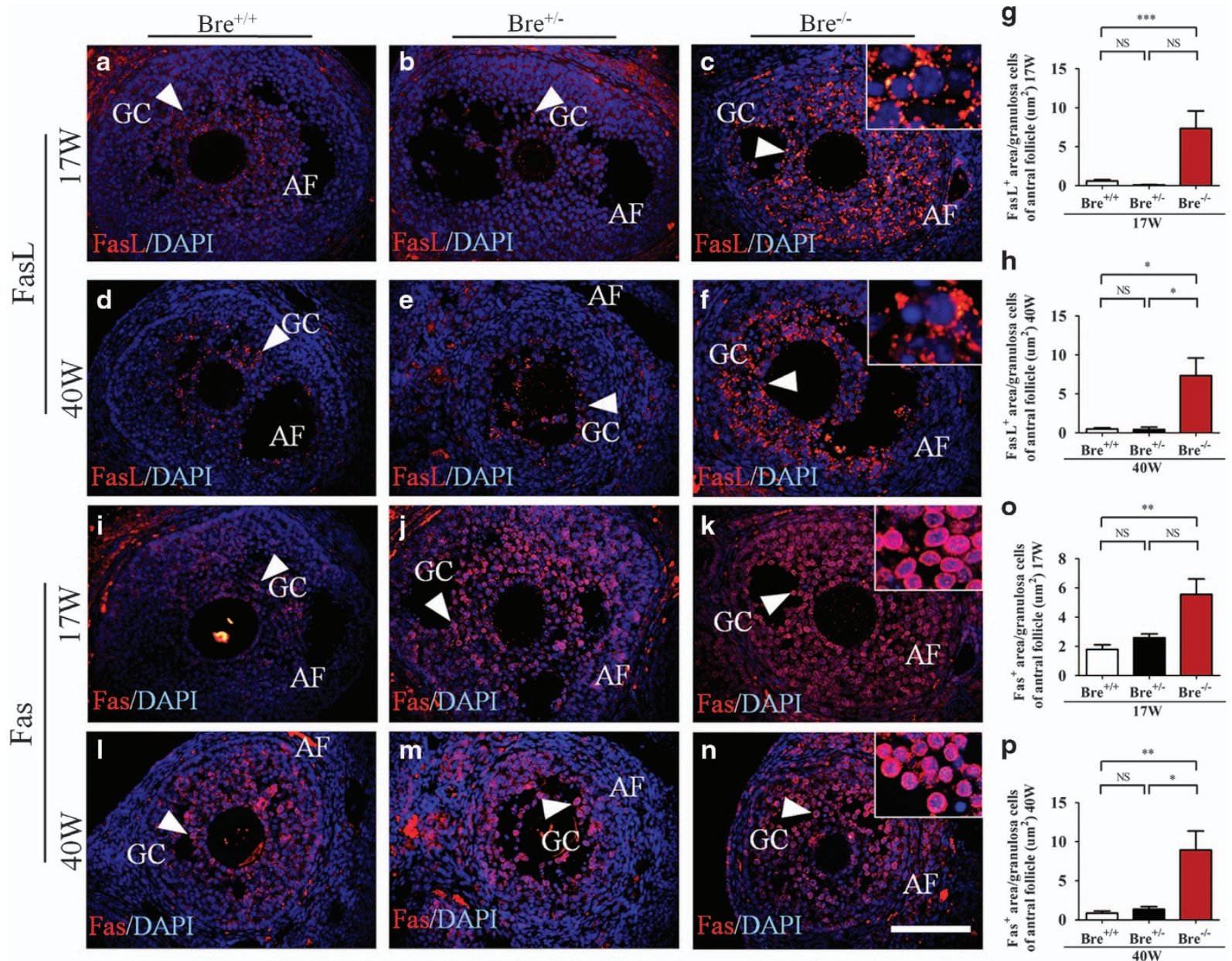

Figure 6 Ovarian sections stained for FasL and Fas expression. Representative micrographs of antral follicles immunofluorescently stained for FasL (a-f) and Fas (i-n) expression in 17- and 40-week-old $\mathrm{BRE}^{+/+}, \mathrm{BRE}^{+/-}$and $\mathrm{BRE}^{-/-}$ovaries. Higher-magnification images are highlighted at top right corners of $\mathbf{c}, \mathbf{f}, \mathbf{k}$ and $\mathbf{n}$. (g and $\left.\mathbf{h}\right)$ Bar charts showing areas that are FasL ${ }^{+}$over the total granulosa cell area of antral follicles, in 17- $(\mathrm{G})$ and or $40-(\mathrm{h})$ week-old $\mathrm{BRE}^{+/+}, \mathrm{BRE}^{+/-}$and BRE ${ }^{-/-}$ovaries. (o and $\left.\mathbf{p}\right)$ Bar charts showing areas that are Fas ${ }^{+}$over the total granulosa cell area of antral follicles, in 17- (o) and or 40- (p) week-old $\mathrm{BRE}^{+/+}, \mathrm{BRE}^{+/-}$and $\mathrm{BRE}^{-/-}$ovaries. AF, antral follicle; GC, granulosa cells. Scale bar $=100 \mu \mathrm{m}$ in a-n

granulosa cells that surround the oocytes at later stages. The granulosa cells of BRE mutants did not express BRE and suggests that it maybe the potential cause of the smaller ovarian size and weight. Moreover, we carefully assessed the distribution of follicles, at various stages of development, in $\mathrm{BRE}^{+/+}, \mathrm{BRE}^{+/-}$and $\mathrm{BRE}^{-/-}$ovaries, and determined that there were significantly fewer follicles (at all developmental stages) in the BRE mutant ovaries. Hence, we investigated whether the reduction in the number of follicles was attributed to reduced cell proliferation, enhanced apoptosis or a combination of both.

Folliculogenesis involves the activation of a small number of primordial follicles, which then develop and pass through the primary, secondary, antral and follicle stages. Only a few of these mature follicles are ovulated, whereas the majority normally undergoes atresia in the mouse. For follicles to develop normally to maturity and not undergo atresia, it involves very precise cellular and molecular interactions. ${ }^{18,19}$ It has been reported that BMP15 and GDF9 were important for inducing follicular cells to differentiate during follicle development and maturity. Our RT-PCR analysis revealed that both Bmp15 and GDF9 expression was significantly reduced in BRE mutant ovarian tissues. Furthermore, Kitl, Pgr and FGFR (follicles development-relevant genes) expression was also repressed. ${ }^{20}$ We propose that the abnormal expression pattern of these genes maybe one of the reason why there were fewer developing follicles in the BRE mutant. However, it is generally recognized that the interaction of autocrine and paracrine effectors, including $\mathrm{FSH}$ and $\mathrm{LH}$, ultimately determines the developmental fate of the developing follicles. ${ }^{18,19}$

Our PAS and Masson's trichrome staining revealed that there were more atretic follicles in the BRE mutants, which may explain why there were fewer follicles in these mutant ovaries. We tried to establish why there were more atretic follicles by focusing on the granulosa cells. These cells are normally indispensable for inducing and supporting the development of the follicles. ${ }^{21,22}$ In this context, we first examine how the absence of BRE affected granulosa cell proliferation. Immunofluorescent staining was performed on 

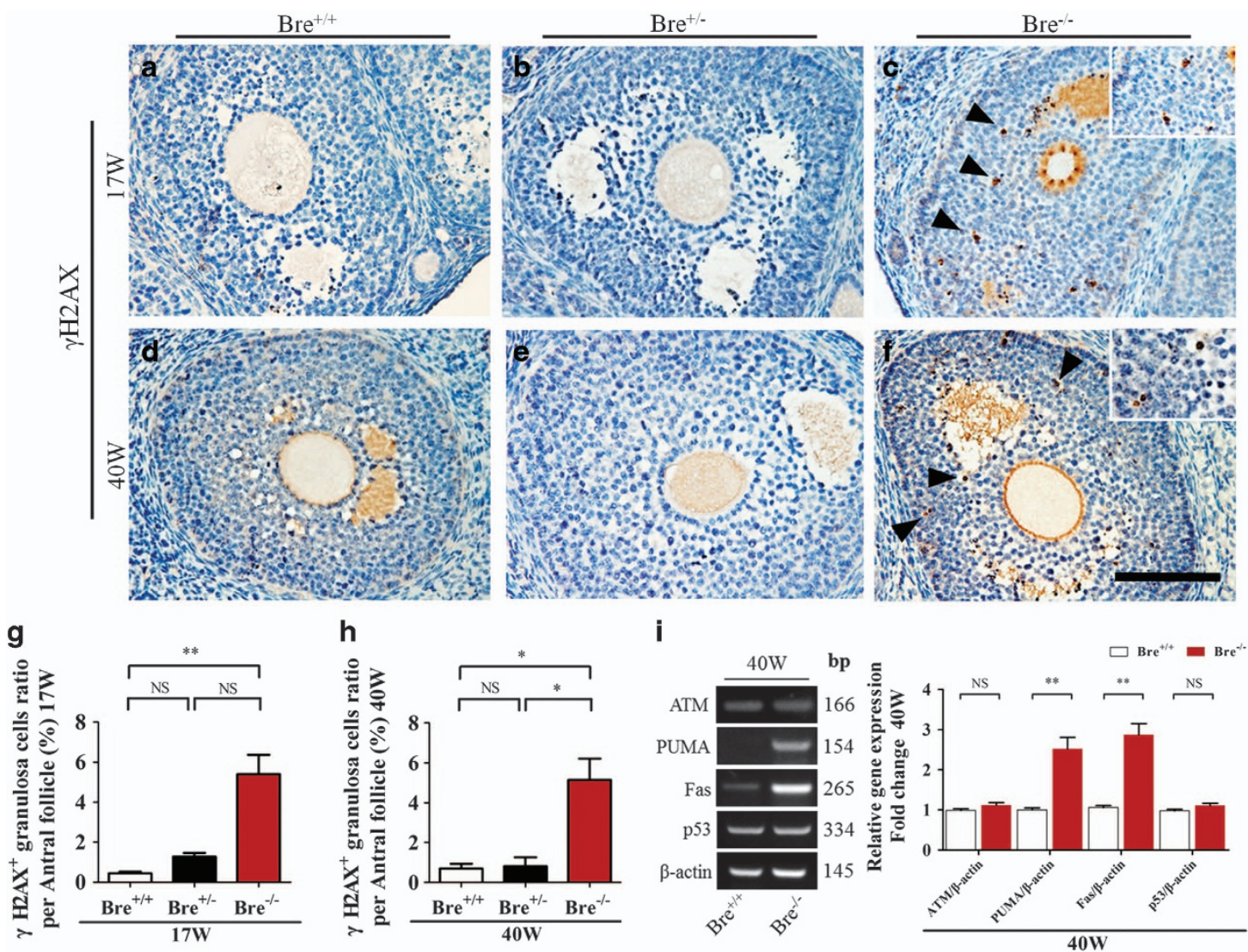

Figure 7 Ovarian sections stained for $\gamma$-H2AX. (a-f) Representative micrographs of 17- and 40-week-old $\mathrm{BRE}^{+/+}$, BRE ${ }^{+/-}$and $\mathrm{BRE}^{-/-}$ovarian sections immunohistochemically stained for $\gamma$-H2AX (marker for DNA double-strand breaks). Higher-magnification image at the top right corner is taken from $\mathbf{c}$ and $\mathbf{f}$. (g and $\mathbf{h}$ ) Bar charts comparing the average number of $\gamma$-H2AX granulosa cells in antral follicles of 17- $(\mathbf{g})$ and $40-(\mathrm{h})$ week-old BRE ${ }^{+/+}, \mathrm{BRE}^{+/-}$and BRE ${ }^{-1-}$ ovaries. (i) Semiquantitative RT-PCR analysis showing ATM, PUMA, Fas and p53 expression in 40-week-old BRE ${ }^{+/+}$and $\mathrm{BRE}^{-/-}$ovaries. The accompanying bar chart indicates the normalized and averaged expression of these genes. Scale bar $=100 \mu \mathrm{m}$ in $\mathbf{a}-\mathbf{f}$

an ovarian section using PCNA and pHIS3 antibodies. We found that there were significantly fewer $\mathrm{PCNA}^{+}$granulosa cells in 17- and 40-week-old $\mathrm{BRE}^{-/-}$follicles than $\mathrm{BRE}^{+/+}$ follicles. We also found that $\mathrm{BrdU}^{+}$granulosa cells were markedly decreased in 17-week-old $\mathrm{BRE}^{-/-}$antral follicles compared with the $\mathrm{BRE}^{+/+}$group. Nevertheless, there was no significant difference in the numbers of $\mathrm{pHIS}^{+}$cells between the two groups. Using flow cytometry of $\mathrm{PI}$ staining, the cell cycle profile of COV434 cells following BRE-siRNA transfection was revealed, which confirmed that the proportion of cells during $S$ phase was reduced after 72-h transfection. The discordance between PCNA, BrdU, pHIS3 expressions and cell cycle analysis suggested that BRE mainly plays a role in the G1-S phase of the cell cycle, which was confirmed by the experimental results of Kim et al. ${ }^{21}$ Cyclins are a family of proteins that control the cell progression through the cell cycle. ${ }^{22}$ Transitions between the different phases of the cell cycle are governed by positive (cyclins and cyclin-dependent kinases (CDK)) and negative (CDK inhibitors) cell cycle regulatory proteins. ${ }^{23}$ CyclinE1, a functional complex as a subunit of CDK2, is required for the G1/S cell cycle transition. Our experiments suggest that silencing BRE can activate the expression of CDK inhibitors p21 and p27, which can block the cell cycle through inhibiting of CyclinE1.

Undoubtedly, the extent of granulosa cell proliferation and apoptosis affects the number of viable follicles that develop to the antral stage. ${ }^{21}$ Increased granulosa cell death is most likely to be the cellular mechanism that directly or indirectly induces follicle atresia. ${ }^{24}$ Quirk et al. have reported that IGF-I and estradiol could promote bovine granulosa cell proliferation and survival because of their increased resistance to apoptosis. ${ }^{25}$ It has been demonstrated that cell cycle arrest and excessive apoptosis of granulosa cells during follicle development could be induced by a high-fat diet. Similarly, we have demonstrated that granulosa cell death (indicated by c-Capase3 labeling) significantly increased in 40-week-old ovaries in the absence of BRE. This implies that BRE conferred an increase in resistance to apoptosis in granulosa cells under normal physiological conditions. Moreover, we have found high level of Fas and FasL expression in $\mathrm{BRE}^{-/}$mouse ovaries - indicating that Fas-FasL signaling has been activated to induce apoptosis in the granulosa cells. The significance of Fas-FasL signaling in granulosa cells has already been confirmed. 


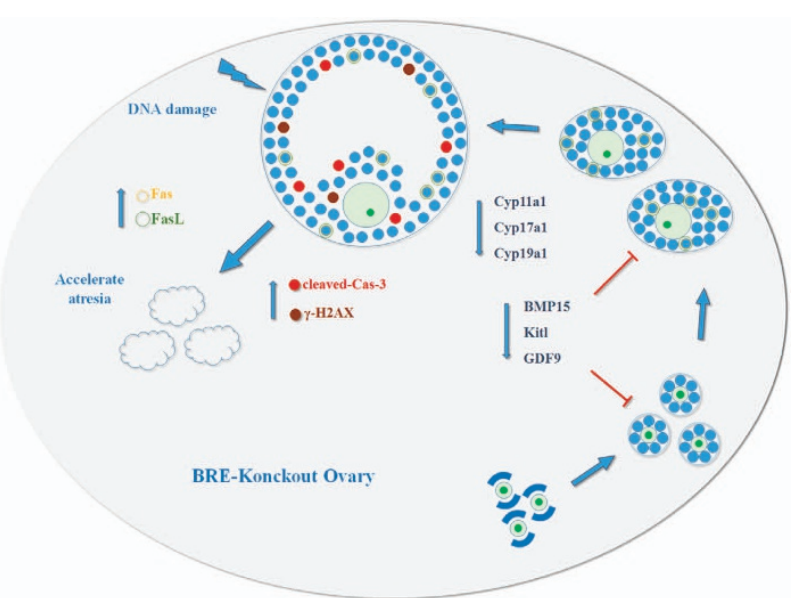

Figure 8 Model depicting how BRE might play a role in the regulation of mouse folliculogenesis and follicular atresia

Next, we asked the question why granulosa cell death was increased in the absence of BRE expression. It has been reported that BRE is mainly involved in DNA damage repair and stress response. Therefore, we decided to determine the presence of $\gamma-\mathrm{H} 2 \mathrm{AX}$ foci, a marker of DNA double-strand breaks, ${ }^{26}$ in $\mathrm{BRE}^{-/-}$and $\mathrm{BRE}^{+/+}$ovaries. We established that there were significantly more $\gamma$-H2AX cells in $\mathrm{BRE}^{-/-}$than in $\mathrm{BRE}^{+/+}$follicles. Moreover, we also revealed that ATM, PUMA, Fas and p53 (DNA damage repair-relevant genes) ${ }^{27}$ expression was significantly upregulated in $\mathrm{BRE}^{-1-}$ ovarian tissues. These findings implied that increased granulosa cell death in BRE mutant follicles maybe attributed to an excessive accumulation of DNA damage-as BRE is not there to assist in DNA repair.

We have schematically illustrated in Figure 8 how we believe BRE influences follicle development and atresia. Briefly, the illustration shows that BRE is mainly expressed in oocyte of primordial follicles, and then it is the specifically expressed granulosa cells that surround the primary, secondary and antral follicles. The expression pattern indicates that BRE might exert its role in folliculogenesis and follicular atresia via the granulosa cells. Moreover, when granulosa cells cannot express BRE, it would lead to growth arrest at $\mathrm{G} 1$ and $\mathrm{G} 2 / \mathrm{M}$ phase, and enhances excess apoptosis (as cells are less efficient in conducting DNA repair). These events in turn induce the follicles to undergo atresia. Nevertheless, there are still more experiments that need to be conducted before we can completely understand how BRE functions in the female reproductive biology.

\section{Materials and Methods}

Mice. BRE-wild-type $\left(\mathrm{Bre}^{+/+}\right)$, -heterozygote $\left(\mathrm{Bre}^{+/-}\right)$and -knockout $\left(\mathrm{Bre}^{-/-}\right)$ mice were obtained from the Chinese University of Hong Kong Animal Centre and maintained at $25^{\circ} \mathrm{C}$ on a $12 \mathrm{~h} \mathrm{light/dark} \mathrm{cycle.} \mathrm{Bre}{ }^{-1-}$ mutant mice were generated based on the Cre/LoxP recombination against a C57/BL/6J background. The BRE

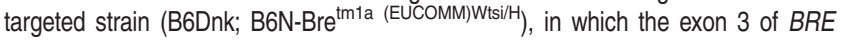
gene is flanked by two loxP sites, was purchased from European Conditional Mouse Mutagenesis Programme (EUCOMM). TNAP-Cre mice (129-Alp ${ }^{\mathrm{tm} 1}$ (cre) Nagy/J, stock number: 008569, Jackson Laboratory, Bar Harbor, ME, USA), which are primordial germ cell-specific transgenic mice, were used to cross with female
$\mathrm{BRE}^{\mathrm{fx} / \mathrm{fx}}$ mice to generate $\mathrm{BRE}^{-1-}$ mice. All of the mice were maintained under a 12 light/12 dark cycle at a constant temperature of $\sim 23^{\circ} \mathrm{C}$ and humidity between 35 and $75 \%$. All animal procedures were approved by AEEC (Animal Experimentation Ethics Committee) of Chinese University of Hong Kong and Hong Kong Government Department of Health. The animal experiments were conducted in accordance with the approved guidelines. ${ }^{28}$

Cell culture and gene transfection. COV434 (human ovarian granulosa cells) was attained from GuangZhou Jennio Biotech Co., Ltd, China (Guangzhou, Guangdong, China). The cells were cultured in a humidified incubator with $5 \% \mathrm{CO}_{2}$ at $37^{\circ} \mathrm{C}$ in six-well plates $\left(1 \times 10^{5}\right.$ cells per ml) containing HAM'S/F-12 (Myclone, Logan, UT, USA) supplemented with 10\% fetal bovine serum (Gibco, Gaithersburg, MD, USA). For the gene transfection, the COV434 cells were transfected by ControlsiRNA (5'-AAGCCUCGAAAUAUCUCCU-3') or BRE-siRNA (5'-CTGGACTGGTG AATTTTCA-3'), with the help of lipofectamin 3000 (Invitrogen, Carlsbad, CA, USA). ${ }^{4}$ Cells were plated to $50-70 \%$ confluence at the time of transfection and the preparation of siRNA-lipid complexes, which were subsequently added to the cells.

Cell cycle analysis. COV 343 cells were transfected with Control-siRNA and BRE-siRNA. At 48 and $72 \mathrm{~h}$ after transfection, the cells were trypsinized, fixed in $70 \%$ ethanol and stored at $4{ }^{\circ} \mathrm{C}$ for overnight. After washing with PBS, the cells were stained with PI solution $(0.04 \mathrm{mg} / \mathrm{ml}$ of PI, $0.25 \mathrm{mg} / \mathrm{ml}$ of RNase A, $0.1 \%$ Triton $X$ in PBS) for $15 \mathrm{~min}$, and then subjected to flow cytometry analysis (Beckman Coulter Gallios flow cytometer, Pasadena, CA, USA). DNA content was determined on counting 10000 cells. Percentage of cells in each cell cycle phase was analyzed using MultiCycle for Windows software (Redmond, WA, USA).

Histology. Briefly, 17- and 40-week-old $\mathrm{Bre}^{+/+}, \mathrm{Bre}^{+/-}$and $\mathrm{Bre}^{-1-}$ ovaries were fixed in $4 \%$ paraformaldehyde at $4^{\circ} \mathrm{C}$ for $24 \mathrm{~h}$. The specimens were then dehydrated, cleared in xylene and embedded in paraffin wax. The embedded specimens were serially sectioned at $5 \mu \mathrm{m}$ using a rotary microtome (Leica, Frankfurt, Germany). The sections were either stained with hematoxylin and eosin, PAS reaction or Masson's trichrome dyes. ${ }^{29}$ The sections were also immunohistochemically stained. The PAS and Masson staining were used to reveal the presence of atretic follicle in the ovarian sections. The stained histological sections were photographed using an epifluorescence microscope and an attached camera (Olympus IX51, Tokyo, Japan; Leica DM 4000B, Frankfurt, Germany) at $\times 200$ magnification.

Classification of developing follicles in ovarian sections. The follicles in the ovarian histological sections were developmentally staged according to their morphology as: primordial, primary, secondary, antral or atretic follicles. Briefly, an oocyte surrounded by a single layer of squamous granulosa cells was classified as a primordial follicle. Oocyte surrounded by a single or several layer/s of cuboidal granulosa cells was classified as a primary or secondary follicle, respectively. When an antrum is present, it was described as an antral follicle. The presence of zona pellucida remnants was classified as an end-stage atretic follicle. ${ }^{30}$ Every fifth and sixth histological sections were selected for comparison and evaluation. Follicles were only counted if they appeared in one histological section but not in the other. ${ }^{30}$

Immunohistological staining. Sections of mouse ovaries were dewaxed, hydrated, incubated in citrate buffer $(\mathrm{pH}$ 6.0) and then heated in a microwave for antigen retrieval. Immunofluorescent staining was conducted on these treated sections using various antibodies. Briefly, the sections were incubated in the following primary antibodies diluted using PBT-NGS: BRE (1:100, Cell Signaling Technology, Boston, MA, USA), (PCNA; 1:400, Santa Cruz Biotechnology, Santa Cruz, CA, USA), p-Histone H3 (pHIS3; 1:400, Santa Cruz Biotechnology), C-Caspase3 (1:100, Cell Signaling Technology), $\gamma$-H2AX (1:100, Millipore, Billerica, Massachusetts, USA), Fas (1:100, Boster, Wuhan, Hubei, China), FasL (1:100, Boster) CD34 (1:100, Abcam, Cambridge, UK) or $\alpha$-SMA (1:100 Abcam) at $4{ }^{\circ} \mathrm{C}$ overnight. Following three $5 \mathrm{~min}$ washes in PBS, the sections were further incubated with goat anti-rabbit IgG conjugated Alexa Fluor 555 (1:1000, Life Technologies, Carlsbad, CA, USA) for $1 \mathrm{~h}$ to detect the presence of BRE, PCNA, C-Caspase3, Fas or FasL. The sections were counterstained with DAPI (1:1000, Life Technologies) at room temperature for $30 \mathrm{~min}$ before examination. For immunohistochemical staining, secondary HRP-linked goat anti-rabbit IgG (1:300, Cell Signaling Technology) was used to reveal pHIS3, CD34 and $\alpha$-SMA staining, or secondary HRP-linked goat anti-mouse IgG (1:300, Cell Signaling Technology) to 
show $\gamma-\mathrm{H} 2 \mathrm{AX}$ staining. Daminobenzidine tetrahydrochloride substrate (DAB kit, MXB, Fuzhou, China) was used to visualize the immunostaining. Photographs were taken of the stained histological sections using an epifluorescence microscope (Olympus IX51, Leica DM 4000B) at ×200 magnification.

In vivo BrdU labeling. BRE-wild-type $\left(\mathrm{Bre}^{+/+}\right)$and $-\mathrm{knockout}\left(\mathrm{Bre}^{-/-}\right)$mice were injected with BrdU (100 mg/kg of body weight) at $10 \mathrm{mg} / \mathrm{ml}$ in PBS intraperitoneally for $2 \mathrm{~h}$ before killing. The ovaries were then extracted and fixed in $4 \%$ paraformaldehyde at $4{ }^{\circ} \mathrm{C}$ for $16 \mathrm{~h}$. For histology, the fixed ovaries were washed, dehydrated and embedded in paraffin wax. The paraffin-embedded ovaries were serially sectioned at $4 \mu \mathrm{m}$. The sections were immunohistologically stained using rat anti-BrdU antibody (1:200; Abcam) and counterstained with hematoxylin for morphological observation. The extent of follicular cell proliferation within follicles was determined by the presence of $\mathrm{BrdU}^{+}$in randomly selected ovarian sections.

RNA isolation and PCR analysis. Total RNA was isolated from 17- and 40-week-old $\mathrm{Bre}^{+/+}, \mathrm{Bre}^{+/-}$and Bre ${ }^{-/-}$ovaries or COV434 cells using Trizol (Invitrogen) according to the manufacturer's instructions. Three ovaries from each group were used. First-strand cDNA was synthesized at a final volume of $25 \mu$ using a SuperScript III First-Strand kit (Invitrogen). Following reverse transcription, RT-PCR amplification of the CDNA was performed using specific primers (Supplementary Figure 1). PCR was performed in a Bio-Rad S1000 Thermal cycler (Bio-Rad, Richmond, CA, USA). The cDNAs were amplified for 30 cycles. One round of amplification was performed at $98^{\circ} \mathrm{C}$ for $10 \mathrm{~s}$, at $60^{\circ} \mathrm{C}$ for $15 \mathrm{~s}$ and then at $72{ }^{\circ} \mathrm{C}$ for $30 \mathrm{~s}$ (Takara, Tokyo, Japan). The PCR products $(20 \mu l)$ were resolved on a $2 \%$ agarose gels (Biowest, Madrid, Spain) in $1 \times$ TAE buffer $(0.04 \mathrm{M}$ trisacetate and $0.001 \mathrm{M}$ EDTA) plus GeneGreen Nucleic Acid Dye (TIANGEN, Beijing, China). The reaction products were visualized using a transilluminator (Syngene, Cambridge, UK) and a computer-assisted gel documentation system (Syngene). qPCR analysis was also performed by SYBR Premix Ex Tag (Takara) using a 7900HT Fast Real-Time PCR system (Applied Biosystems, Foster City, CA, USA). The primer sets used for the qPCR are provided in Supplementary Figure 2. Each of these experiments was replicated at least three times. The RT-qPCR results were produced from four independent sets of experiments. The housekeeping gene, $\beta$-actin, was run in parallel to confirm that equal amounts of RNA were used in each reaction. The ratio intensity for the fluorescently stained bands of genes of interest, and $\beta$-actin was calculated and normalized to quantify the level of gene expression.

Image acquisition and analysis. Whole ovaries were photographed using a fluorescence stereomicroscope (Olympus MVX10) and analyzed imaging software (Image-Pro Plus 6.0 Media Cybernetics, Media Cybernetics, MD, USA). Sections of the stained ovaries were photographed using an epi-fluorescent microscope (Olympus IX51, Leica DM 4000B) at $\times 200$ and $\times 400$ magnification, and analyzed using an Olympus software (Leica CW4000 FISH).

For quantification of proliferation, apoptosis and DNA damage, we counted the number of $\mathrm{PCNA}^{+}, \mathrm{pHIS3}^{+}, \mathrm{C}^{-}$Caspase $3^{+}$and $\gamma-\mathrm{H}_{2} \mathrm{AX}^{+}$granulosa cells versus total $\mathrm{DAPl}^{+}$granulosa cells for each antral follicle in 17- and 40-week-old mouse ovaries $\left(\mathrm{Bre}^{+/+}, \mathrm{Bre}^{+/-}\right.$and $\left.\mathrm{Bre}^{-/-}\right)$. The results were then compared between each group with the follicles only at the same developmental stage. For immunofluorescent staining of 17-40-week-old ovaries, total Fas ${ }^{+}, \mathrm{FasL}^{+}, \mathrm{CD}_{4} 4^{+}$and $\alpha$-SMA $^{+}$granulosa or theca cells in antral follicles were counted. ${ }^{31}$ Statistical analysis was performed using a SPSS 19.0 software (SPSS software, Armonk, NY, USA), and the data were presented as mean \pm S.E.M. Six ovaries of each group $\left(\mathrm{Bre}^{+/+}, \mathrm{Bre}^{+/-}\right.$and $\left.\mathrm{Bre}^{-l-}\right)$ were used.

Data analysis. Data analyses and construction of statistical charts were performed using GraphPad Prism 5 software (GraphPad Software, La Jolla, CA, USA). The results were presented as the mean value $(\bar{x} \pm$ S.E.M.). Statistical analysis was performed using IBM SPSS Statistics 19.0 software (IBM SPSS Statistics software, Armonk, NY, USA). Statistical significance was determined using an independent sample's $t$-test, and non-parametric independent samples KruskalWallis test. $P<0.05$ was considered to be statistically significant.

\section{Conflict of Interest}

The authors declare no conflict of interest.
Acknowledgements. This study was supported by NSFC grant (81571436, 31300963 and 31401230), Science and Technology Planning Project of Guangdong Province (2016B030229002, 2014A020213008 and 2014A020221091), Science and Technology Program of Guangzhou (201510010073 and 201710010054), Guangdong Natural Science Foundation (2016A030311044), General Research Grant (14100315), and Research Grant of Key Laboratory of Regenerative Medicine, Ministry of Education, Jinan University (ZSYX-M-00001 and ZSYX-T-00001).

1. Li L, Yoo H, Becker FF, Ali-Osman F, Chan JY. Identification of a brain- and reproductiveorgans-specific gene responsive to DNA damage and retinoic acid. Biochem Biophys Res Commun 1995; 206: 764-774.

2. Miao J, Panesar NS, Chan KT, Lai FM, Xia N, Wang Y et al. Differential expression of a stress-modulating gene, BRE, in the adrenal gland, in adrenal neoplasia, and in abnormal adrenal tissues. J Histochem Cytochem 2001; 49: 491-500.

3. Ching AK, Li PS, Li Q, Chan BC, Chan JY, Lim PL et al. Expression of human BRE in multiple isoforms. Biochem Biophys Res Commun 2001; 288: 535-545.

4. Tang MK, Wang CM, Shan SW, Chui YL, Ching AK, Chow PH et al. Comparative proteomic analysis reveals a function of the novel death receptor-associated protein BRE in the regulation of prohibitin and p53 expression and proliferation. Proteomics 2006; 6: 2376-2385.

5. Gu C, Castellino A, Chan JY, Chao MV. BRE: a modulator of TNF-alpha action. Faseb J 1998; 12: 1101-1108.

6. Chen E, Tang MK, Yao Y, Yau WW, Lo LM, Yang X et al. Silencing BRE expression in human umbilical cord perivascular (HUCPV) progenitor cells accelerates osteogenic and chondrogenic differentiation. PLOS ONE 2013; 8: e67896.

7. Yu Y, Wei W, Wang Y, Xu C, Guo Y, Qin J. Simple spinning of heterogeneous hollow microfibers on chip. Adv Mater 2016; 28: 6649-6655.

8. McGee EA, Hsueh AJ. Initial and cyclic recruitment of ovarian follicles. Endocr Rev 2000; 21: 200-214.

9. Raju GA, Chavan R, Deenadayal M, Gunasheela D, Gutgutia R, Haripriya G et al. Luteinizing hormone and follicle stimulating hormone synergy: a review of role in controlled ovarian hyper-stimulation. J Hum Reprod Sci 2013; 6: 227-234.

10. Matsuda F, Inoue N, Manabe N, Ohkura S. Follicular growth and atresia in mammalian ovaries: regulation by survival and death of granulosa cells. The J Reprod Dev 2012; 58: 44-50.

11. Bertoldo MJ, Bernard J, Duffard N, Mermillod P, Locatelli Y. Regulating pre-antral follicle development: a brake on depletion of the ovarian reserve. Gynecol Obstet Fertil 2013; 41: 540-543.

12. Fauser BC. Observations in favor of normal early follicle development and disturbed dominant follicle selection in polycystic ovary syndrome. Gynecol Endocrinol 1994; 8: 75-82.

13. Hsueh AJ, McGee EA, Hayashi M, Hsu SY. Hormonal regulation of early follicle development in the rat ovary. Mol Cell Endocrinol 2000; 163: 95-100.

14. Yu YS, Sui HS, Han ZB, Li W, Luo MJ, Tan JH. Apoptosis in granulosa cells during follicular atresia: relationship with steroids and insulin-like growth factors. Cell Res 2004; 14: 341-346.

15. Murdoch WJ. Programmed cell death in preovulatory ovine follicles. Biol Reprod 1995; 53: 8-12.

16. Liu ZH, Yue KZ, Ma SF, Sun XS, Tan JH. Effects of pregnant mare serum gonadotropin (eCG) on follicle development and granulosa-cell apoptosis in the pig. Theriogenology 2003; 59: $775-785$.

17. deMoura MD, Chamoun D, Resnick CE, Adashi EY. Insulin-like growth factor (IGF)-I stimulates IGF-I and type 1 IGF receptor expression in cultured rat granulosa cells. Endocrine 2000; 13: 103-110.

18. Roche JF. Control and regulation of folliculogenesis-a symposium in perspective. Rev Reprod 1996; 1: 19-27.

19. Scaramuzzi RJ, Baird DT, Campbell BK, Driancourt MA, Dupont J, Fortune JE et al. Regulation of folliculogenesis and the determination of ovulation rate in ruminants. Reprod Fertil Dev 23: 444-467.

20. Shiina H, Matsumoto T, Sato T, Igarashi K, Miyamoto J, Takemasa $S$ et al. Premature ovarian failure in androgen receptor-deficient mice. Proc Natl Acad Sci USA 2006; 103: 224-229.

21. Kim JM, Yoon YD, Tsang BK. Involvement of the Fas/Fas ligand system in p53-mediated granulosa cell apoptosis during follicular development and atresia. Endocrinology 1999; 140: 2307-2317.

22. Galderisi U, Jori FP, Giordano A. Cell cycle regulation and neural differentiation. Oncogene 2003; 22: 5208-5219.

23. Wolf G, Shankland SJ. P27Kip1: the "rosebud" of diabetic nephropathy? J Am Soc Nephrol 2003; 14: 819-822.

24. Kim JM, Boone DL, Auyeung A, Tsang BK. Granulosa cell apoptosis induced at the penultimate stage of follicular development is associated with increased levels of Fas and Fas ligand in the rat ovary. Biol Reprod 1998; 58: 1170-1176.

25. Quirk SM, Cowan RG, Harman RM, Hu CL, Porter DA. Ovarian follicular growth and atresia: the relationship between cell proliferation and survival. J Anim Sci 2004; 82:(E-Suppl) E40-E52.

26. Zhao X, Yang G, Toyooka T, Ibuki Y. New mechanism of gamma-H2AX generation: Surfactant-induced actin disruption causes deoxyribonuclease I translocation to the nucleus and forms DNA double-strand breaks. Mut Res 794: 1-7. 
27. Roos WP, Kaina B. DNA damage-induced cell death by apoptosis. Trends Mol Med 2006; 12 : $440-450$.

28. Shi W, Tang MK, Yao Y, Tang C, Chui YL, Lee KK. BRE plays an essential role in preventing replicative and DNA damage-induced premature senescence. Sci Rep 2016; 6 : 23506.

29. Li Y, Wang XY, Zhang ZL, Cheng X, Li XD, Chuai M et al. Excess ROS induced by AAPH causes myocardial hypertrophy in the developing chick embryo. Int J Cardiol 2014; 176: $62-73$

30. Myers M, Britt KL, Wreford NG, Ebling FJ, Kerr JB. Methods for quantifying follicular numbers within the mouse ovary. Reproduction 2004; 127: 569-580.

31. Chen MJ, Chou CH, Chen SU, Yang WS, Yang YS, Ho HN. The effect of androgens on ovarian follicle maturation: Dihydrotestosterone suppress FSH-stimulated granulosa cell proliferation by upregulating PPARgamma-dependent PTEN expression. Sci Rep 2015; 5: 18319 . (c) (1) Cell Death and Disease is an open-access journal published by Nature Publishing Group. This work is licensed under a Creative Commons Attribution 4.0 International License. The images or other third party material in this article are included in the article's Creative Commons license, unless indicated otherwise in the credit line; if the material is not included under the Creative Commons license, users will need to obtain permission from the license holder to reproduce the material. To view a copy of this license, visit http://creativecommons.org/licenses/by/4.0/

(C) The Author(s) 2017

Supplementary Information accompanies this paper on Cell Death and Disease website (http://www.nature.com/cddis) 